\title{
PRECEDENTES NO DIREITO BRASILEIRO - PRECEDENTES, INSTRUMENTO EFICAZ PARA ALCANCE DA JUSTIÇA EFETIVA
}

\section{ARTIGO ORIGINAL}

CARNEIRO, Dioclécio Salomão ${ }^{1}$

CARNEIRO, Dioclécio Salomão. Precedentes no Direito Brasileiro - Precedentes, instrumento eficaz para alcance da justiça efetiva. Revista Científica Multidisciplinar Núcleo do Conhecimento. Ano 05, Ed. 07, Vol. 01, pp. 05-18. Julho de 2020.

ISSN: 2448-0959,

Link de acesso: https://www.nucleodoconhecimento.com.br/lei/direito-brasileiro

\section{RESUMO}

A pesquisa busca tratar do tema "precedentes no direito brasileiro" voltado para a ideia de tornar o processo cada vez mais justo e democrático, seja através da ampla participação ativa das partes na lide, seja pela uniformização dos julgados com mesma reflexão jurídica, afim de produzir o resultado justo para as partes envolvidas no processo. Para isso será discutido a concretização, doutrina, especificidades e parâmetros de aplicação desses precedentes. Destaca-se, ainda, a importância da discussão sobre o tema, pois o Estado Julgador aliado à sociedade, necessita observar e construir um lastro jurídico que se torne referência de justiça, estabilidade social e principalmente que a população tenha nos diferentes ramos do direito, o instrumento da prática cidadã, galgando correções de desigualdades sociais históricas produzidas na sociedade brasileira.

Palavras-chave: Direito Constitucional, democracia, precedente, justiça.

\footnotetext{
1 Mestrando em Direito Constitucional - Direitos Fundamentais e Democracia, Bacharel em Direito e Ciências Contábeis.
} 


\section{INTRODUÇÃO}

O problema da incerteza macula a atuação dos tribunais superiores no Brasil. Tornouse comum encontrar decisões em sentidos diametralmente opostos proferidas por uma mesma Turma do Superior Tribunal de Justiça. E ainda mais grave, tais decisões são tomadas sem haver qualquer preocupação em justificar os posicionamentos conflitantes. Notável perceber que falta aos tribunais a preocupação com a uniformidade, segurança, galgando assim o instituto da incerteza, como também a instabilidade do sistema jurídico brasileiro. De nada adianta ter ampla promulgação de leis se os entendimentos e interpretação construída a respeito delas são os mais variados conforme o bel prazer do Estado Julgador. A Casa de Leis acaba por ter o efeito contrário do que espera o legislador, que é conferir segurança aos cidadãos, justiça e aplicação da lei conforme a foi construída. As interpretações legislativas são tantas e de um extremo a outro que sequer possibilita visualizar se a legislação possui ou não sua constitucionalidade, muito menos se será aplicada ao caso concreto seguindo a vontade do Poder Legislativo (expressão da vontade popular), sendo, portanto, a decadência da segurança jurídica-democrática na formação do Direito brasileiro.

\section{O ESTUDO DOS PRECEDENTES NO DIREITO BRASILEIRO. A CONCRETIZAÇÃO DOS PRECEDENTES JURÍDICOS BRASILEIROS. COMO A DOUTRINA ABSORVE ESSES PRECEDENTES DAS CORTES BRASILEIRAS OU O INVERSO}

A Constituição de 1988 passou por diversas emendas legislativas com o intuito de adequar e atualizar frente as necessidades sociais que a cada legislatura tende a ampliar no horizonte de um sistema estável e de plena prática cidadã. Historicamente os últimos anos vem se destacando pelo extenso período democrático aliado ao maior crescimento da economia. O Poder Judiciário como um todo, além do Ministério Público, galgou amplitude em suas atuações, atribuições e competências, autorizadas pela Carta Magna cidadã, afim de buscar arduamente a efetiva concretude dos direitos sociais fundamentais, seja de liberdade coletiva e individual. No entanto, ainda carece 
de maior avanço, no contínuo fortalecimento das instituições democráticas que garantem os direitos fundamentais. (ZANETI JR, 2015). Importante salientar que a todo momento ocorrem ataques e interferências contrárias a sistemática social do Estado brasileiro, principalmente nas casas legislativas federais e estaduais, advindas muitas vezes do próprio Poder Executivo respaldado pelas mais diversas justificativas colocando em cheque as conquistas já realizadas e outras por vir ao cidadão brasileiro cuja Constituição já os prevê.

Sendo assim, o sistema da Civil Law tem-se a ideia cuja estabilidade jurídica da legislação permaneceria vinculada de forma pura e simples a aplicação da lei e o magistrado seria então o fio condutor dessa concretização no mundo fático. (DONIZETTI, 2015). No entanto a lei pura por ser interpretada de várias formas e tendências, algumas vezes pressupõe julgamentos de valor moral, o que acaba por prejudicar a essência da lei objeto de sua criação, logo tem-se prejudicado a segurança jurídica, condição essa tão importante para o Estado Democrático de Direito. Diante dessa criticidade enfrentada, aparece como mecanismo de ajuste do centro de justiça observado na carga valorativa da lei produzida, a figura do sistema de precedentes, cujo busca manter uma espécie de lastro interpretativo nas sentenças dado soluções idênticas para casos fáticos idênticos, que possibilitem certamente de mesmo fundamento jurídico, consequentemente reduzindo demandas excessivas, além do tempo desprendido para casos de mesma natureza que adentram ao sistema judiciário.

Para o modelo Romano-Germânico, cujo teve sua predominância na Europa continental, tem a lei como a "espinha dorsal" do direito. Entende-se esse sistema como um comando geral e abstrato, cujo tem finalidade de abraçar, em sua moldura, a prepotência de contemplar todos os fatos jurídicos futuros. Se diz que o ajuste da norma ao fato concreto, se dá pelo raciocínio dedutivo, iniciando-se do comando geral para estreitar na situação particular. Para esse sistema, os julgados, em vias de regra, não contemplam efeitos que possam vincular outros, portanto se insurgem como fonte secundária do direito. Pode-se até abrir horizonte para compreensão, inspirar iniciativas ao poder legislativo, no entanto não produzem nova fonte de norma 
jurídica. Por outro lado, Common Law, sistema esse originário de países de colonização anglo-saxã, os julgamentos decorrem como sendo um grande arcabouço jurídico vinculante e geral para futuros fatos jurídicos de idêntico teor causal. A norma nesse caso, tem sua origem no fruto da decisão jurídica, sendo, portanto, aplicada, de forma indutiva. (MARINONI, 2013). A determinação jurídica parte-se da compreensão realizada frente aos fatos significativos apresentados, portanto mais fragmentada, com elo de ligação na particularidade e senso de justiça para a demanda, não se preocupando em síntese, em produzir resoluções abrangentes e sistemáticas, por isso menos comum o uso da lei "crua" nesse sistema do que no direito RomanoGermânico.

Desta forma, entende-se que a lei perde sua condição de fonte principal e única do direito e passa a estar subordinada à Carta Magna, estando, portanto, em consonância com os dizeres constitucionais, principalmente no que refere as questões que diz respeito aos direitos fundamentais. É sabido que cabe aos juízes não somente declarar a lei ao caso concreto, mas também prestar o controle de constitucionalidade da mesma além dos atos normativos. (LOURENÇO, 2011). Necessário entender que o Poder Judiciário concretiza a lei em seu plano fático para o concreto, devendo então proceder da técnica de compreensão do núcleo essencial da norma.

É possível dizer que o precedente não poderá ser anunciado de forma única e completa e sim partindo-se das distinções, ampliações e reduções que os precedentes estão sujeitos de forma sistemática ao refino interpretativo do Poder Judiciário. Vislumbrando-se sempre da participação de todos os atores processuais, com intento de novas questões a serem analisadas, garantindo assim uma espécie de delimitação daquele precedente/norma extraída. (NUNES; HORTA, 2015). Importante salientar que não se ignora o texto legislativo e tampouco a doutrina, pelo contrário, é desses textos que são extraídos, no decorrer do tempo de análise, uma vertente de precedentes que se constrói em dado momento, produzindo assim estabilidade específica a essa técnica, o distinguishing, cujo amolda importante processo de germinação e maturação do direito jurisprudencial. 
Com a experiência, obviamente em razão do fato de vivermos numa sociedade razoavelmente pluralista e que valoriza a democracia, pode-se dizer que, até certo ponto, essa abertura hermenêutica já existe de forma difusa entre os sujeitos, seja pelo modo como os agentes políticos aplicam a Constituição nas diversas instâncias de decisão, resultando ao menos no ampliado círculo de participantes na concretização constitucional, assegurando-se também, mesmo que em grau mínimo, a influência da sociedade sobre aqueles cuja função espera-se a melhor interpretação constitucional. Diante disso, é necessário institucionalizar procedimentos que ampliem a intervenção de terceiros no processo de interpretação e aplicação da lei fundamental. (COELHO, 1998). Todavia, independentemente das peculiaridades, cabe ressaltar que no âmbito da jurisdição constitucional, os sujeitos que não participarem da relação processual, seja não assumindo alguma posição no processo ou até ignorarem sua existência, poderão considerar-se não alcançados pelos efeitos da coisa julgada e, por consequência, reclamarem injustiça feita.

\section{O PRECEDENTE COMO DIREITO UNIVERSAL. O PRECEDENTE COMO MEIO DE SE ALCANÇAR A JUSTIÇA EFETIVA. ANÁLISE DO CASO COM SUAS ESPECIFICIDADES E A CONTROVÉRSIA DA APLICAÇÃO UNIVERSAL DO PRECEDENTE}

Um fato histórico é que nas sentenças produzidas pela Câmara dos Lordes (último tribunal de apelação) cujos são lembrados por deterem a condição de revisar julgados de tribunais iniciais nos casos em que um desses seus participantes identificam oposições ao sistema da Common Law. Ainda assim esses mesmos julgados ainda que antagônicos são de grande importância, quando inéditos, pois frutificam em análise novos precedentes, atualizados e melhor aplicados aos fatos concretos e assim passam a ser seguidos pelos juízes até que um novo seja tornado precedente por essa análise. Cita-se o exemplo do Reino Unido para o assédio sexual referenciados no Sex Discrimination Act 15, de 1975, e o Employment Rights Act 16, de 1996. Nessas leis não se declara de forma objetiva o assédio sexual, referenciando apenas as condutas ditas ilícitas que denigrem a dignidade dos trabalhadores. (STOLZ, 2006). Para essa Lei de Discriminação Sexual, coíbe-se todo 
comportamento discriminatório em desfavor das mulheres seja no ambiente familiar, laboral ou social. Consequentemente, comportamentos de repúdio, ofensa, lesão, assédio por interpretação judicial direcionados às mulheres no âmbito do trabalho são considerados atos discriminatórios e, como tais, ilícitos e puníveis.

Cabe ressaltar que o grande obstáculo que se depara o direito nos últimos tempos é o de gerir os problemas e conflitos produzidos pela alteridade do convívio em sociedade no instante que o sujeito tem acesso as facilidades do cotidiano e então ocorrem os conflitos de interesses. (SAUSEN, 2011). Principalmente em países que vêm se desenvolvendo de gradual e lenta, atrasada, como o caso do Brasil, no que tange em especial a realização e concretude dos mandamentos fundamentais constitucionais, e em face disso o Estado no anseio de buscar a realização de políticas sociais que acaba por afetar diretamente o Poder Judiciário, o que tem ocorrido com bastante frequência, acaba por se utilizar em modelo padronizado, de forma muitas vezes indevida os precedentes como uma espécie de medida para todo e qualquer caso jurídico sem se quer avaliar os impactos produzidos no orçamento público por exemplo.

Por isso, uma vez elaborado o precedente-texto, a respectiva aplicação tem evidência no permeável instrumento de aplicação legislativa ou de outro escrito normativo. Em qualquer caso, o juiz deve interpretar o texto e, sob o ponto de vista positivista, deve estar vinculado ao que declarar a partir desse. (DA FONTE, 2017). A teoria cuja vinculação do magistrado ao texto jurídico (reflexo da interpretação) está na mesma base do positivismo jurídico, independentemente dessa norma ter sido construída a partir da legislação, do precedente normativo ou outra referência pertinente. A vinculação do aplicador à norma não é particular ao regime dos precedentes, razão pela qual convém colher alguns resultados quanto a teoria do atrelamento do juiz à lei, aproveitando e adaptando as conclusões ao contexto da aplicação dos precedentes.

A Constituição de 1988 cujo demarcou o Direito Processual Civil brasileiro, demonstrara a preocupação em garantir o total direito entre as partes, buscou-se assim a estabilidade jurídica, a vedação de julgados inesperados ou de surpresa para 
fatos de semelhança, pedido e causa de pedir. Com o advento da Carta Magna de 1988 foi possível construir um código de processo civil contemporâneo ligando esse código às normas constitucionais relacionadas. Desta forma tem-se a Constituição como fonte de origem para um processo justo, com princípios, normas e valores que garantem a resolução do conflito de forma a assegurar o acesso perene ao judiciário e também a tutela adequada. (SCHELEDER, 2006). Importante destacar não só o acesso quantitativo, mas também de qualidade de justiça durante o processo, de forma que ocorra a efetivação das garantias constitucionais previstas no processo legal cujo busca assim coibir decisões atentatórias à dignidade das partes.

Com isso, segundo defende a doutrina jurisprudencialista, será possível garantir ou, ao menos, aumentar o grau de previsibilidade e de isonomia fronte as conclusões jurídicas, cujos juízes e tribunais serão obrigados a respeitar suas próprias decisões e, mais do que isso, a adotar as interpretações sobre à lei e à Constituição fixadas por tribunais hierarquicamente superiores. Desta forma, a construção de um modelo de Precedentes vem significar obediência quase mecânica às decisões de tribunais hierarquicamente superiores, como nova tentativa de solução do caos interpretativo de normas em que o Brasil vive. (ANAIS DO, 2017). De outro lado, parte da comunidade jurídica (não simpatizante à vinculação de precedentes) argumenta que essa medida afeta a independência do Judiciário e de seus integrantes, cerceando a liberdade dos juízes de decidirem consoante seu convencimento pessoal acerca das provas e do direito, assim "engessando" a decisão jurídica e fechando as possibilidades de apreciação dos casos. Não só isso. Afirmam que essa importação irrefletida do Stare Decisis do Common Law para o Civil Law é incompatível com a Constituição e com a teoria jurídica contemporânea, porquanto insinua transformar o direito posto em um "sistema" de precedentes e teses sem observar que há um problema "metodológico" na teoria dos precedentes no que diz respeito a diferenciação entre quem interpreta e quem aplica o precedente.

Assim, não há parâmetros seguros para se afirmar que o sistema Common Law é melhor que o Civil Law, pois cada um possui suas peculiaridades próprias e se adequam conforme a necessidade do ordenamento jurídico de cada país, através de 
seus movimentos históricos e culturais. Logo, o que importa não é necessariamente o sistema jurídico adotado em si, mas sim, a qualidade das decisões judiciais. (PAGLIARINI, 2018). Para tanto, os tribunais brasileiros, em específico o Supremo Tribunal Federal, necessita usar da prerrogativa que detém, defender a Constituição Federal e utilizar os mecanismos que lá se encontram para agir de forma justa perante a sociedade, e não achar que "fazer justiça" é colocar sua opinião conforme os ministros acharem mais pertinente nas decisões em que lhe competem apreciar e justificar que é "para o bem da sociedade" decidir um caso totalmente ao contrário de suas decisões passadas, as quais supostamente já foram pacificadas, e principalmente decidir contra a Carta maior do Estado. Desta forma, não haverá sistema jurídico que sustente tantas controvérsias fundamentadas em nada, o que consequentemente ao invés de como os defensores dos Precedentes brasileiros relatam que com a instrução dos mesmos haverá mais segurança jurídica, não haverá segurança alguma, ao passo que a praxe que vem sendo praticada nos tribunais brasileiros é de modificar algo que já está decidido e positivado.

\section{O PRECEDENTE E O PRAGMATISMO NO DIREITO BRASILEIRO. PARÂMETROS A SEREM OBSERVADOS NA CONSTRUÇÃO DO PRECEDENTE. ATUALIZAÇÃO DO PRECEDENTE FIRMADO PARA DIZER O DIREITO}

Os Precedentes, na teoria da Common Law, tratam-se de julgados que antecedem outros, servindo como ponto de início para a decisão de novos fatos jurídicos. Para fatos de idêntica reflexão jurídica, que se apresentam ao judiciário para decisão, partindo do ideal que já solucionada e pacificada no Tribunal. O Brasil de forma mais recente utilizara o termo "precedente" para atribuir a alguns julgados judiciais quando os sãos declarados para servirem de balizas ou parâmetros em medida para vinculação dos julgamentos futuros em fatos idênticos. (LEMOS JUNIOR; BATISTA, 2019). Desta forma, o precedente desde o seu pronunciamento, garante a vinculação de força obrigatória. Destaca-se ainda que no sistema Common Law, ao contrário, toda e qualquer decisão jurídica, desde que alicerçada em fundamentos, teorias, princípios, correntes e valores aceitos daquele sistema jurídico, passam a vigorar 
como um precedente servindo de parâmetro nos julgados futuros de fatos semelhantes.

Dois fatos jurídicos de mesma natureza e identidade resolverem-se com o mesmo julgado é algo tão lógico e compreensível, cujo exemplo de um cidadão que se vê na obrigação de arcar com uma condenação, tendo outro julgado de idêntica situação vislumbrar de seu desfecho totalmente avesso num grau de absolvição pelo simples ato de um processo estar na primeira, segunda, vara ou turma como exemplo. (MAMAN, 2014). Dito isso, como explicar e esclarecer a esse cidadão a justiça realizada em ambos os casos idênticos e ainda informar que no sistema jurídico brasileiro não há o precedente vinculante posto, e, portanto, se vê obrigado a recorrer aos agravos, gerando mais demanda num modelo já sufocado de processos. Qualquer leigo ou mesmo teóricos do direito se posicionam contrariamente às soluções praticadas divergentes de idênticos fatos jurídicos, violação se dá contra a igualdade, segurança jurídica e mesmo a eficiência da tutela jurisdicional.

$\mathrm{Na}$ vertente dos precedentes, em que pese o contrário dessa afirmação, o entendimento atribuído aos Estados Unidos da América frente a filosofia foi através do desenvolvimento da Escola do Pragmatismo. Destarte, raras escolas da filosofia demonstram de forma clara o pensamento moderno como a frieza calculista do Pragmatismo. Trata-se da industrialização do pensamento filosófico, da transformação do pensar em uma commodity, um bem com valor diretamente relacionado a sua efetividade e aplicação prática. (GUERRA; DE ALMEIDA NETO; MARCOS, 2017). Não existe nada que traduza melhor o pensamento do homem moderno que o mecanismo basilar adotado pelos Pragmatistas: uma ideia (da mesma forma que uma ferramenta) só "presta" se seus efeitos práticos forem bons e bom é aquilo que é útil. Neste diapasão, o Pragmatismo Filosófico contamina o pensamento jurídico e o induz com seus ideais de tornar-se uma ciência racional, objetiva e eficaz. Hoje, pode-se afirmar que uma das vertentes mais influentes da teoria jurídica contemporânea é sem dúvida o Pragmatismo Jurídico.

O propósito do fortalecimento desse instituto do precedente objetiva questões operacionais e jurídicas no intuito da planificação uniforme e estável dos julgados 
jurídicos, que naturalmente irão produzir melhor homogeneidade nos processos jurídicos que por sua vez reduzirão ações de fatos discutidos já consolidados, ademais prevalecerá melhor e maior segurança no sistema como um todo, adstringindo análises que não condizem com todo o arcabouço já estudado e prevalecido, principalmente no quesito às inovações tanto da doutrina quanto do Poder Judiciário que destoam do poder legislativo emanado do povo. De tal forma a teoria da Common Law pode sim trazer melhorias para o sistema jurídico brasileiro, haja visto a carência notória de melhoria operacional frente a enorme demanda de processos judiciais que adentram todos os dias, além de que a falta de tramitação em tempo razoável já sinaliza uma face de injustiça. (LEMBI; DE ARAÚJO LIMA, 2013). É, portanto, necessário o perfil e aperfeiçoamento dessa teoria para que se possa instaurar mesmo que à passos curtos na evolução do modelo jurídico brasileiro. Para tanto no contexto de Imannuel Kant todas as coisas que podemos conceber neste mundo ou mesmo, de maneira geral, fora dele, não há nenhuma que possa ser considerada como boa sem restrição, salvo uma "boa vontade".

Mesmo com o aperfeiçoamento das leis, o mundo atual clama contra a pouca eficiência na prestação da tutela jurisdicional, mas, não é o que de fato se pode constatar na maioria das demandas que lhe são submetidas com o intuito de os litígios serem solucionados a contento. A efetividade da jurisdição está diretamente ligada ao resultado pretendido com o que se obtém após a decisão. Ou seja, não basta apenas garantir o livre alcance para a justiça, mas também que as decisões sejam aptas a construir meios concretos da vida em sociedade. (FORTES, 2017). Daí decorre a utilidade do processo que este se dê em tempo razoável, de forma justa e que seja eficiente e produza ganhos no âmbito fático. A Constituição diz, no artigo 5º, inciso XXXV, expressamente que a lei não excluirá da apreciação do Poder Judiciário lesão ou ameaça à direito. Assim para que se garanta a segurança jurídica, deve-se assegurar a previsibilidade das decisões dos órgãos jurisdicionais. Desta forma, o artigo 5ำ da Constituição Federal, no inciso LXXVIII, informa o princípio da celeridade processual e determina o tempo racional do processo. A partir deste princípio, buscase no Brasil uma nova etapa da efetividade jurisdicional, a da concretização dos direitos reconhecidos pelo Poder Judiciário. Hoje, inevitavelmente, as leis têm de 
traçar procedimentos simples, claros, ágeis. Portanto, para se alcançar a eficiência e eficácia, o Poder Judiciário precisa atuar no contexto de efetividade, atendendo para os casos de maior reflexão, decidindo pelo correto e proferindo sua decisão fundamentada, adequada, justa, sem abrir mão das peculiaridades do fato concreto. Assim o princípio Constitucional, preceituado no artigo 93, inciso XI, "toda decisão deve ser motivada, sob pena de nulidade". Dessa forma o Novo Código de Processo Civil, no parágrafo $1^{0}$ do artigo 499, dispõe critérios que deverão ser observados para a adequada fundamentação das decisões. Pois, decisões mal motivadas podem vir a ser nulas ou inexistentes, dependendo da natureza da omissão judicial. Observa-se na atualidade da justiça brasileira, decisões conflitantes sobre a mesma situação jurídica, o que dificulta a previsão de como se dará o entendimento acerca de uma mesma questão jurídica e da alteração de entendimento nos tribunais Superiores, gerando assim um alto grau de instabilidade. (FORTES, 2017). O princípio da segurança jurídica busca a previsibilidade, ou seja, o magistrado ao resolver o caso deve zelar pela estabilidade da jurisprudência. Bem como, tem o condão de assegurar que não apenas as situações consolidadas outrora sejam respeitadas, como também que daí advenham legítimas expectativas, condutas e comportamentos nas situações presentes, que são pautadas no princípio da proteção da confiança.

O precedente tem ligação ao fato que o deu origem, não podendo haver ruptura, pois os argumentos que fundamentam o julgado, irá produzir fonte jurídica, um poder que produzirá efeitos concretos vinculantes a norma, daí fonte argumentativa, interpretativa e até de imposição da norma baseada naquela compreensão retratada, produzindo dessa maneira o direito, cujo estará sempre tratando de questões do cotidiano social e o conhecimento posto. O pensamento racional utilizado, cujo justifica o julgado para de certa maneira realizar a imposição do conhecimento verdadeiro além da melhor interpretação do significado pretendido pela norma, deverá por consequência prevalecer para além das próximas decisões, subtraindo a interpretação contrária, de tal maneira a criar uma hierarquia do contexto interpretativo, para então construir o controle do direito assim como sua fonte, de forma a estabilizar o sistema jurídico. Desta forma, considera-se o precedente como também recurso argumentativo e sustentação para o conhecimento jurídico, 
vinculante para casos com mesmas características e peculiaridades apontadas em última análise ao caso a ser decidido. (FRANZÉ; PORTO, 2016). Para isso não se quer prestar à sociedade o poder irrestrito de criação e fonte do direito, tampouco de produzir regulamentações autônomas, e sim as bases estruturais do conhecimento jurídico soberano ao impor seus preceitos de produção normativa. É permissivo que o direito se auto regulamente, desenvolver-se a cada julgado, porém a técnica do Overruling sempre estará disposta ao Estado. A proposta do Overruling e do Distinguish denotam fatores de que implicam na discussão fundamental relacionada a análise dos precedentes jurídicos como também a teórica declaratória, constitutiva ou positiva do direito, haja visto o precedente estar também no rol de fonte do direito, para isso é prudente o juiz saber quão poder regulamentar e sua legitimação ao se utilizar do paradigma na resolução do caso concreto.

\section{CONCLUSÃO}

Em que pese um Estado que prima pela instabilidade jurídica de seu ordenamento, decisões e sentenças conflitantes, além da produção incessante de leis sem qualquer aplicação fática para a prática da justiça, regulação e organização da sociedade e Estado é de se esperar como consequência a desordem nas políticas públicas, corrupção, investimento público inadequado além do aumento dos índices de degradação dessa sociedade haja visto a violência na escalada do grau máximo, contas públicas que a cada ano superam déficit a ponto de suspender em muitos casos a atividade básica estatal de atendimento à saúde por exemplo.

Nesse cenário o Estado brasileiro se perde no lodo das políticas meramente de governo e nunca na história políticas de Estado, que se perpetuem para o futuro, para com o planejamento responsável, objetivo e progressista, mas ao contrário o país vive um eterno avanço e depressão cíclicos dos seus índices de democracia e bem-estar da população. Essa instabilidade já se inicia dentro do próprio Estado Julgador cujo exerce as interpretações das leis de forma a prejudicar o interesse público, no sentido de declarar sentenças e julgados conflitantes e despadronizados de norte à sul. Isso é de extremo prejuízo à segurança jurídica dos cidadãos, do próprio Estado, da economia como um todo o que acaba refletindo naturalmente na anomia de normas, 
enfraquecimento do poder judiciário e demonstração clara de que o direito aplicado é fruto da conveniência do Estado Julgador, sem observância a construção de um lastro jurídico que se torne referência de justiça e estabilidade social.

\section{REFERÊNCIAS}

ANAIS DO, Simpósio Brasileiro de Processo Civil. Academia Brasileira de Direito Constitucional. Hermenêutica, Argumentação Jurídica E Precedentes Judiciais: O Papel Do Juiz Na Conformação Dos Provimentos Decisórios, 2017.

COELHO, Inocêncio Mártires. Peter Häberle e a interpretação constitucional no direito brasileiro. Revista de Direito Administrativo, v. 211, p. 125-134, 1998.

DA FONTE, Leonardo Avelar. O Juiz Pode Ser A "Boca Do Precedente"?. Parahyba Judiciária, v. 10, n. 10, 2017.

DONIZETTI, Elpídio. A Força Dos Precedentes No Novo Código De Processo Civil. Direito UNIFACS-Debate Virtual, n. 175, 2015.

FORTES, Clarisse Grimaldi. Precedentes Judiciais: A Importância Da Coerência Nas Decisões Judiciais Para A Segurança Jurídica. IV Encontro de pesquisas judiciárias da Escola Superior da Magistratura do Estado de Alagoas, 2017.

FRANZÉ, Luís Henrique Barbante; PORTO, Giovane Moraes. Elementos Da Teoria Do Precedente Judicial. Revista Em Tempo, v. 15, p. 55-71, 2016.

GUERRA, Gustavo Rabay; DE ALMEIDA NETO, Luiz Mesquita; MARCOS, Henrique Jerônimo Bezerra. O Processo Civil Pragmático E O Constitucionalismo Dialógico: Pressupostos Para Uma Discussão Sobre Ativismo Judicial. Rei-Revista Estudos Institucionais, v. 3, n. 1, p. 649-676, 2017.

LEMBI, João Lucas Cavalcanti; DE ARAÚJO LIMA, Diego. A Aplicação Da Tópica Como Parâmetro A Ser Observado Para A Formação De Precedentes Judiciais, 2013. 
LEMOS JUNIOR, E.; BATISTA, C. (2019). Precedentes Judiciais E O Sistema Jurídico Brasileiro De Tradição Civil Law. Revista Direito Em Debate, 27(50), 50-63. https://doi.org/10.21527/2176-6622.2018.50.50-63.

LOURENÇO, Haroldo. Precedente judicial como fonte do direito: algumas considerações sob a ótica do novo CPC. Revista Eletrônica Temas atuais de processo civil, v. 1, n. 6, 2011.

MAMAN, Tobias Scheffer de. Precedentes no direito brasileiro: a tradição jurídica ocidental entre instrumentos, métodos e história. 2014.

MARINONI, Luiz Guilherme et al. Precedentes obrigatórios. Palestra Editores, 2013.

NUNES, Dierle; HORTA, André Frederico. Aplicação de precedentes e distinguishing no CPC/2015: Uma breve introdução. Coleção Grandes Temas do Novo CPC. Salvador. Juspodvim, 2015.

PAGLIARINI, Alexandre Coutinho; SPALLER, Amanda Viega. Precedentes Judiciais No Brasil E A Crítica Hermenêutica Do Direito. Themis: Revista da Esmec, v. 16, n. 2, p. 15-43, 2018.

PUGLIESE, William. Precedentes e a civil law brasileira: interpretação e aplicação do novo código de processo civil / William Pugliese. -- São Paulo: Editora Revista dos Tribunais, 2016. -- (Coleção o novo código processo civil / coordenação Luiz Guilherme Marinoni, Sergio Cruz Arenhart, Daniel Mitidiero).

SAUSEN, Dalton. A utilização (in) devida dos precedentes: uma reflexão para além do aspecto quantitativo da prestação jurisdicional. Revista do Tribunal de Contas do Estado de Minas Gerais, 2011.

SCHELEDER, Adriana Fasolo Pilati. O significado constitucional do acesso à justiça. Revista Brasileira de Direito Constitucional, v. 7, n. 2, p. 144-160, 2006.

STOLZ, Sheila. O Direito a não ser discriminado por razão de gênero segundo a Scottish Court of Session: Apreciação de um Precedente Judicial. O direito a não ser 
discriminado por razão de gênero segundo a Scottish Court of Session: apreciação de um precedente judicial, 2006.

ZANETI JR, Hérmes. O valor vinculante dos precedentes. Salvador: JusPodivm, 2015.

Enviado: Novembro, 2019.

Aprovado: Julho, 2020. 